\title{
Experimental Study on Some Mechanical Properties of Papercrete Concrete
}

\author{
Shewit Birhane, Mikyas Mesfin, Werku Koshe* \\ Email address: \\ Shewitbirhane157@gmail.com (S. Birhane),Worku.koshe@yahoo.com (W. Koshe) \\ ${ }^{*}$ Corresponding author
}

Department of Construction Technology \& Management, Diredawa Institute of Technology, Diredawa University, Diredawa, Ethiopia

To cite this article:

Shewit Birhane, Mikyas Mesfin, Werku Koshe. Experimental Study on Some Mechanical Properties of Papercrete Concrete. Advances in Materials. Vol. 6, No. 1, 2017, pp. 1-6. doi: 10.11648/j.am.20170601.11

Received: November 10, 2016; Accepted: December 16, 2016; Published: February 16, 2017

\begin{abstract}
This study presents an experimental approach for the use of Papercrete for construction. Green materials are now the preferred material for construction since they are capable of lighter weight and affordable. Based on recent studies, alternative building materials are cost effective, light weight when dry, and efficient to use. This study started from referring different literatures concerning the topic and related ideas up to conceptualization and design of the trial ratio to be used in testing. The goal of the study is to utilize Papercrete toward attaining a sustainable development. Testing and Analysis of the result provided sufficient data to prove whether it is possible to use Papercrete concrete as a construction material according to the data's the $14^{\text {th }} \& 28^{\text {th }}$ day compressive strength of the ratios $1: 1: 0.5,1: 1: 1,1: 1: 1.5$ has become 1, 0.5, $0.24 \& 2.1,0.98,0.56 \mathrm{MPa}$ respectively. For the water absorption test $23.1 \%, 34.3 \%, 33.07 \%$ respectively for the weight $7.2 \mathrm{~kg}, 6.6 \mathrm{~kg}, 6.1 \mathrm{~kg}$ respectively and additionally for the density test $774.193,709.677$, $655.9139 \mathrm{~kg} / \mathrm{m}^{3}$ respectively. Comparison between the samples formulated was used to analyze if it may be used in the future as a construction elements.
\end{abstract}

Keywords: Papercrete Hollow Block, Compressive Strength, Waste Paper, Low Cost Material, Light Weight Material

\section{Introduction}

Since the large demand has been placed on building material industry especially in the last decade owing to the increasing population which causes a chronic shortage of building materials. The civil engineers have been challenged to convert the industrial wastes to useful building and construction materials. This experimental study which investigates the potential use of waste paper for producing a low-cost and light weight composite brick as a building material [1]. Papercrete material has been found many years ago but rediscovered recently. Papercrete is a material consisting of waste paper and Portland cement. The waste paper and Portland cement is mixed by the use of water to create paper cement pulp, which can then be placed into a mould, allowed to dry and be used as a durable building material. It should be understood that Papercrete is relatively a new idea with a limited knowhow.

\subsection{Objective of the Research}

The major objective of this thesis is to investigate the possibility of using paper as an alternative material for making a hollow block by satisfying the specific ones.

- To provide optional construction material.

- To adopt the use of waste material.

- To reduce the environmental impacts caused by the burning and dumping of waste papers.

\subsection{Literature Review}

Lightweight concretes

Lightweight concrete is known for its low density and thermal conductivity which is great to consider especially in our country that needs to be economical to gain significant advantages. It is also an effective material to reduce dead load capacity of a certain structure.

Types of lightweight concrete

NO-FINES CONCRETE 
From past studies and researches, No-fine Concrete is defined as a lightweight type of concrete which is basically composed of fine aggregates and cement. Though this idea is basically focused on the percentage or amount of cement in the mixture, the greater the amount of cement, the better is the mixture. It maintains large air voids and doesn't form laitance layers.

\section{LIGHTWEIGHT AGGREGATE CONCRETE}

This type of concrete was categorized because it uses porous lightweight aggregate of low specific gravity instead of normal concrete aggregates. This type of concrete is a natural aggregate which can be pumice, scoria and other volcanic and artificial aggregates from blast site or slag.

\section{AERATED CONCRETE}

This type of concrete doesn't use coarse aggregate and is specified as a mortar. The idea is to insert or to inject air or other gas into its cement slurry and fine aggregates during its plastic condition. This type of lightweight concrete is suitable for roof insulation and for some partitions wall applications because of its comparative strength and low shrinkage factor.

\section{APPLICATION OF LIGHTWEIGHT CONCRETE}

The application of Lightweight concrete has been practiced mostly in the US and England. The construction for shipbuilding and concrete blocks for infrastructure are its main uses. Pumice and Foamed blast furnace slag are the commonly used aggregates which are lighter than common aggregates used for construction. Because of advancement in technology, the idea of using lightweight concrete expands as it was used in different variety of construction applications.

\section{PAPERCRETE}

Papercrete is a "new" experimental material that is not yet produced from many commercial manufacturing companies. Actually, Papercrete was first patented in 1928 [5] and recently rediscovered by individuals that are curious to examine the possibilities and potentials of such material that started re-experimenting with it again. Papercrete presents high environmental potential due to the fact that it replaces an amount of cement by the use of paper and the total weight, cost and $\mathrm{CO}_{2}$ emissions during production are reduced [6]. It has potentials to become a future building material for lightweight applications thanks to its low cost and high recycle paper content. [7] Papercrete is mainly made from recycled paper that is combined usually with sand and Portland cement [8] creating a composite material that is malleable and can be casted and molded in various forms and shapes. Papercrete can be casted and pressed into bricks, blocks and panels and can be used in the building industry for a variety of applications [7]. Papercrete can be used also as a casting material in-situ that can be applied directly to walls as "gunned/shotcrete" [7] to construct monolithic structures. Waste paper can be derived from newspaper, junk mail, magazines, and books. It is noticed that some types of paper work better than others; newspaper is most commonly used because it produces consistent results [6]. It is a lightweight material with good insulating properties [8] and when contains cement it is also fire resistant.

\subsection{Methodology}

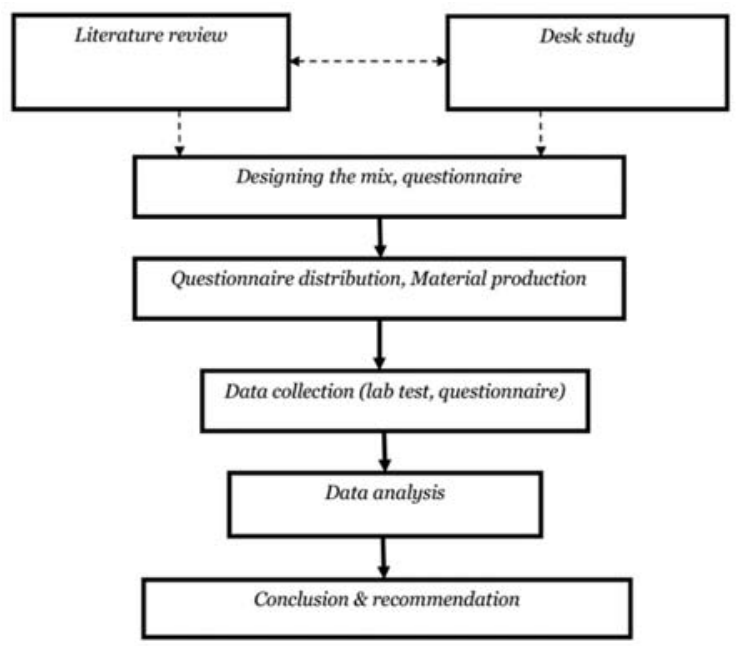

Figure 1. Methodology.

\section{Methods in Producing Papercrete}

\subsection{Collection of Materials}

\subsubsection{Cement}

Cement is one of the binding materials in this project. Cement is the important building material in today's construction world and Portland pozzolanic cement, CES-28, GRADE: 32.5N CEM II, CERT NO. 320086. Type cement has been used for this research.

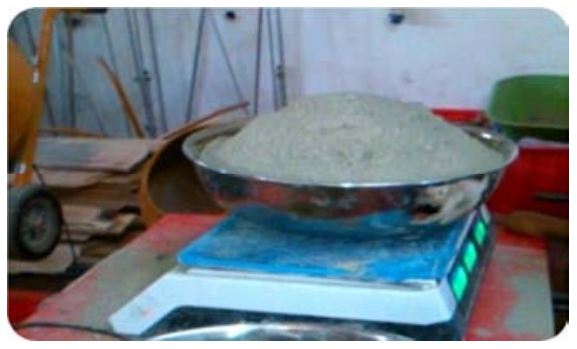

Figure 2. Cement.

\subsubsection{Sand}

The sand obtained from local resource was used in concrete to cast test hollow blocks. All the sand particles should be fine therefore our sand passes $3.35 \mathrm{~mm}$ sieve and the sand was washed in order to reduce the silt content, silt content is 4.6.

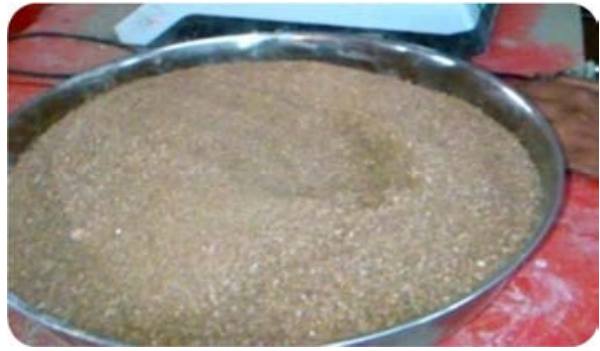

Figure 3. Sand. 


\subsubsection{Paper}

Is a thin material produced by pressed together moist fibers of cellulose pulp derived from wood, rags or grasses, and drying them into flexible sheets. It is a versatile material with many uses, including writing, printing, packaging, cleaning, and a number of industrial and construction processes. [10]

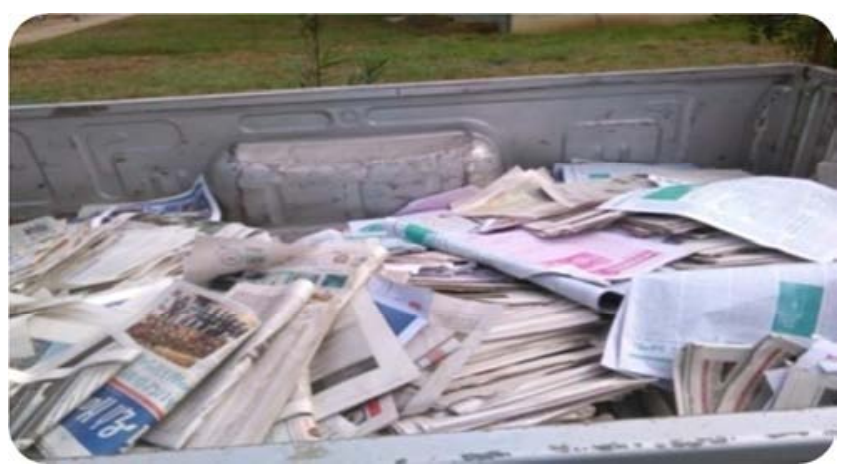

Figure 4. Paper

\subsubsection{Water}

Is a color less, odorless, transparent, liquid which plays a major role on the reaction of the paper with cement. [11] It should be free from organic matter and drinkable water was used.

\subsection{Pulp Generation}

The papers, which were collected, cannot be used directly. It should be made into paper pulp before mixing with other ingredients.

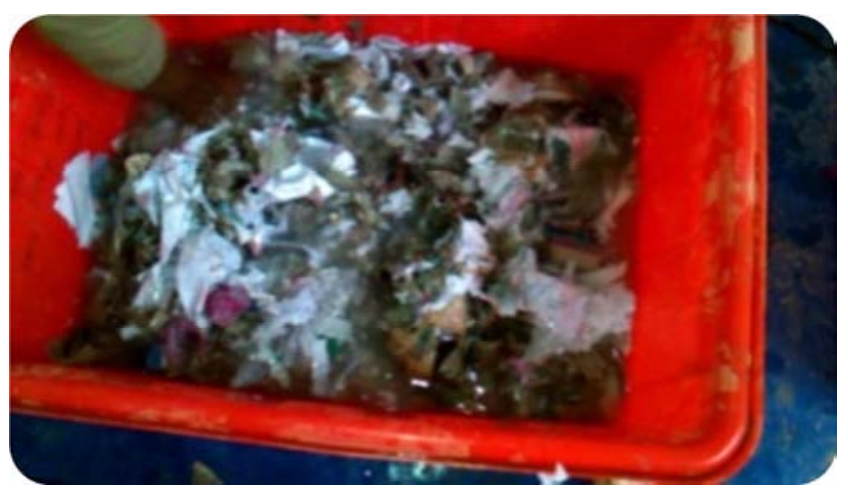

Figure 5. Soaked paper.

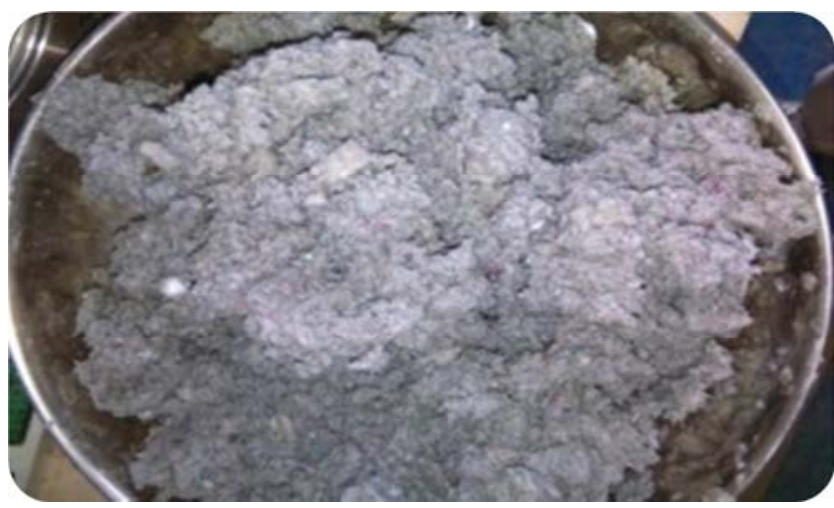

Figure 6. Paper pulp.

Before the production begins the ratios have been determined. The table below shows the ratio of the samples.

Table 1. Papercrete sample specimen ratio.

\begin{tabular}{lllll}
\hline Identification mark & Ingredients (\%) & & & \\
\hline & Paper & cement & sand & Water ( pulping + mixing ) \\
\hline S1 & 0.5 & 1 & 1 & $9+7=16$ lit. \\
S2 & 1 & 1 & 1 & $12+4=16$ lit. \\
S3 & 1.5 & 1 & 1 & $15+7=22$ lit. \\
\hline
\end{tabular}

The papers were chopped and kept in the plastic tank with water for 3 days otherwise until the papers degrade into a paste like form. Then the paper was taken out from water and taken to the mixer machine to make it as a paper pulp.
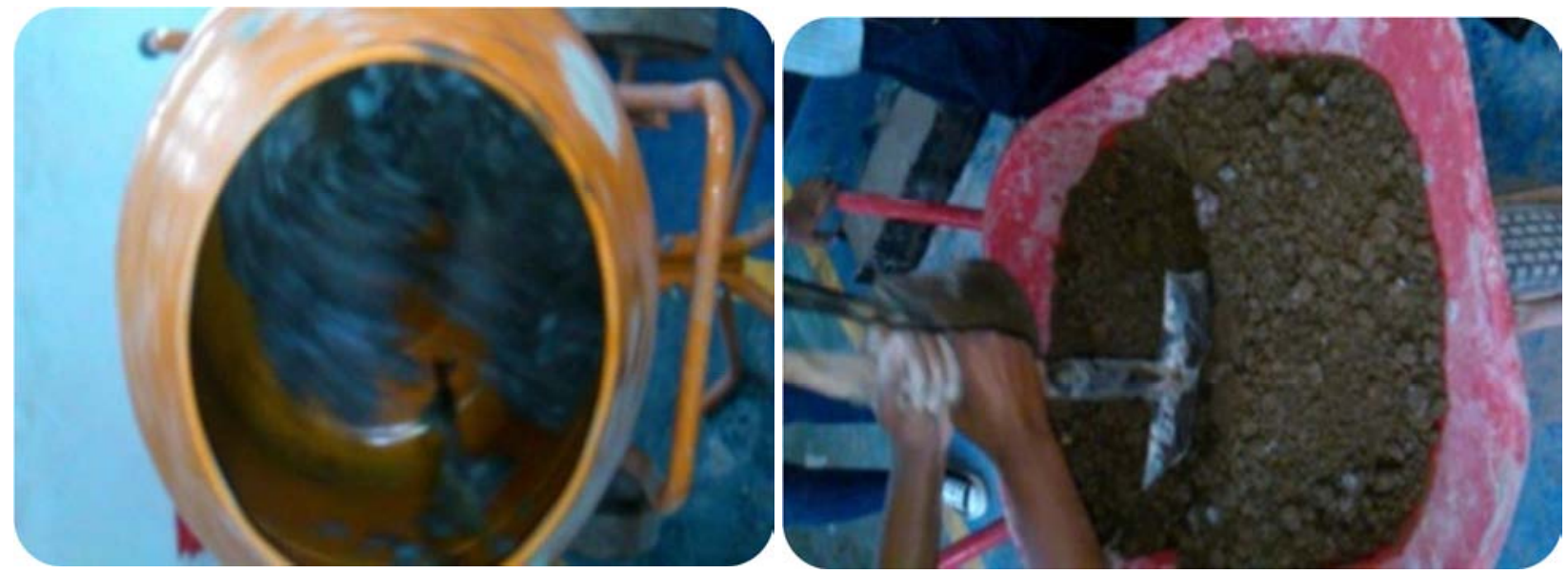


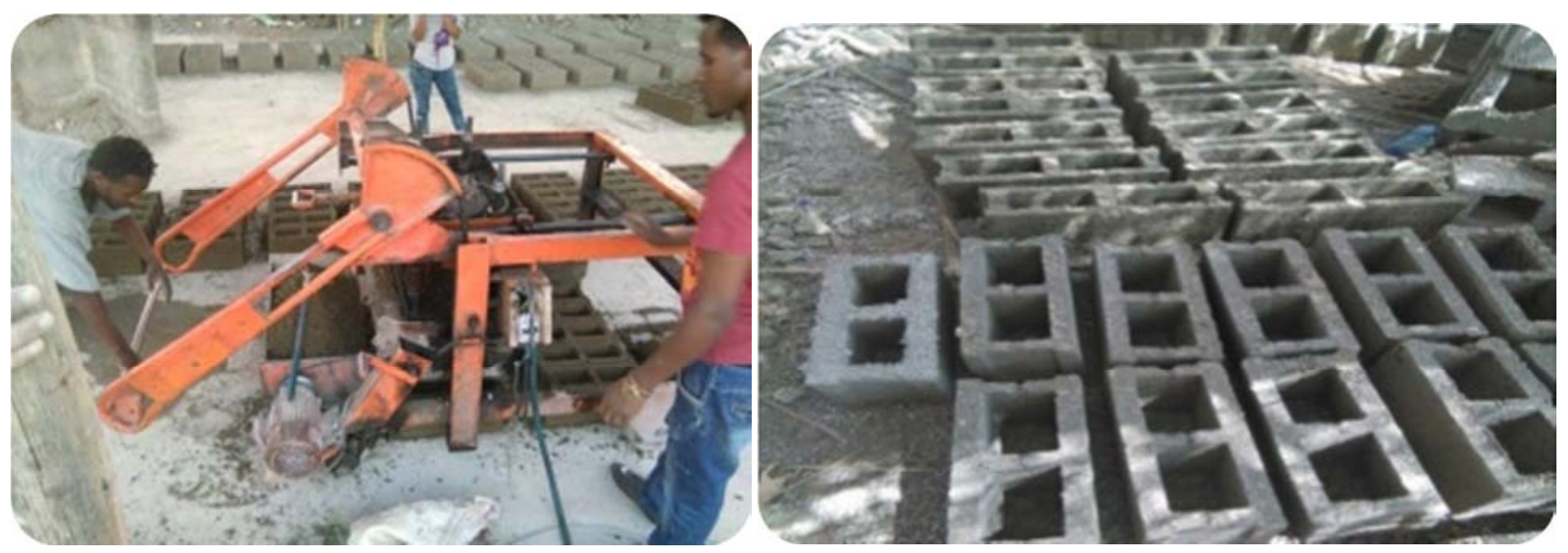

Figure 7. Production process of Papercrete hollow block.

\section{Results and Discussion}

\subsection{Results of Survey Data}

The graph shows the abundance and the disposal way of the randomly selected sample companies in Diredawa city.

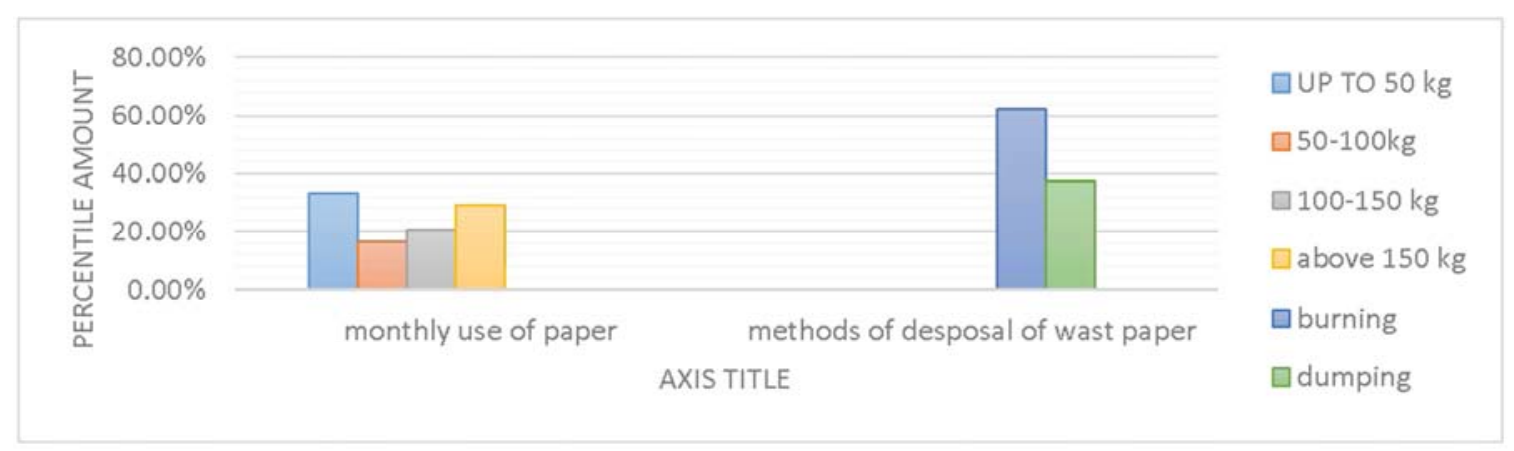

Figure 8. Monthly paper consumption \& disposal method of sample companies.

\subsection{Compressive Strength Test}

The Papercrete specimens was tested for their capacity at compression stage. Sample Specimens are tested after 14 days to have comparative data on how the behavior of Papercrete develops as it matured. Here is the Papercrete sample after the compression test. The figure shows how the Papercrete behaved when compressed under load and the graph shows the average compressive strength of the given samples.

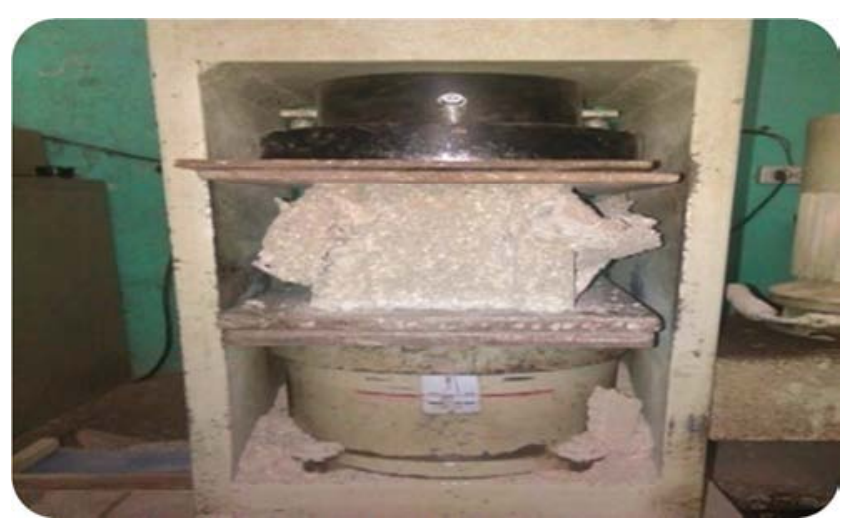

Figure 9. Papercrete hollow block under compression.

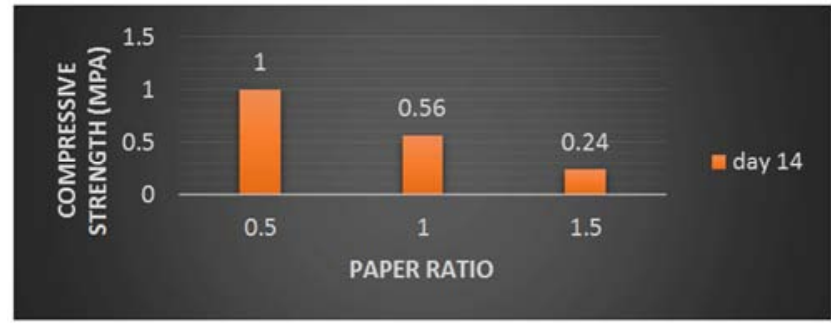

Figure 10. Compressive strength of the Papercrete sample.

Table 2. Percentile water absorption amount of the samples.

\begin{tabular}{llll}
\hline $\begin{array}{l}\text { Ratio (cement: } \\
\text { sand: paper) }\end{array}$ & $\begin{array}{l}\text { Initial weight } \\
(\mathbf{m} 1) \mathbf{~ k g}\end{array}$ & $\begin{array}{l}\text { Final weight } \\
\left(\mathbf{m}^{2}\right) \mathbf{~ k g}\end{array}$ & $\begin{array}{l}\text { Water absorption \% } \\
(\boldsymbol{m} \mathbf{1}-\boldsymbol{m} \mathbf{2})\end{array} * \mathbf{1 0 0}$ \\
\hline $1: 1: 0.5$ & 6.91 & 8.5 & 23.01 \\
$1: 1: 1$ & 5.21 & 7 & 34.3 \\
$1: 1: 1.5$ & 5.26 & 7 & 33.07 \\
\hline
\end{tabular}

\subsection{Water Absorption Test}

After completely immersing the blocks for 24 hours, water was wiped-off the surfaces of the blocks. Each of the blocks was then weighed. The mass of each of the blocks before curing was subtracted from its mass after 24 hours of curing in water in order to determine the mass of water absorbed. 
The water absorption in percent was determined by, considering in percentage terms, the ratio of the mass of water absorbed to the initial mass of the Papercrete block before it was cured in water.
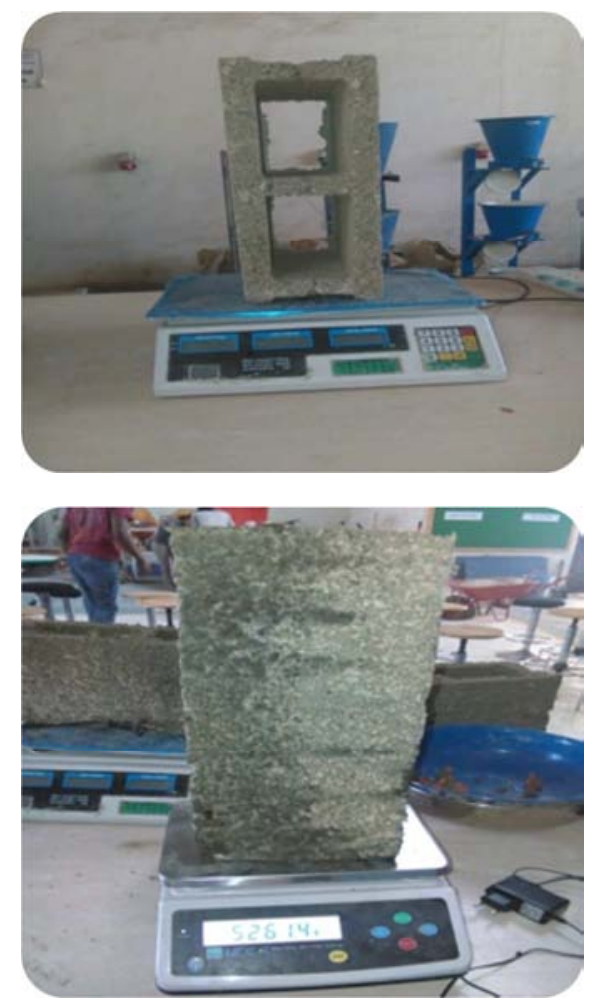

Figure 11. Weighing Papercrete hollow block.

\subsection{Weight}

All the given blocks were weighed and their average weight was taken depending on their ratio to be compared with the ordinary ones since the main objective is to determine if it is light weight. All blocks were weighed in a well-conditioned electronic weighing machine. The following are the weight of the blocks.

Table 3. Average weight of the samples.

\begin{tabular}{llll}
\hline \multicolumn{3}{l}{ Average individual ratio weight } & \\
\hline Ratios & $1: 1: 0.5$ & $1: 1: 1$ & $1: 1: 1.5$ \\
Weight $(\mathrm{kg})$ & 7.2 & 6.6 & 6.1 \\
\hline
\end{tabular}

\subsection{Density}

Considering the dimensions of hollow block 150x 200x400 $\mathrm{mm}^{3}$ deducted by $\left(90 \times 150 \times 200 \mathrm{~mm}^{3}\right) \times 2$ dimension of the hollow their densities were determined by dividing their mass, by its effective volume. The density of the Papercrete hollow block has been determined as follows, as the higher the paper amount the lesser the density.

Table 4. The density of the samples.

\begin{tabular}{llll}
\hline Ratio & weight & Dimension $\left(\mathbf{m}^{\mathbf{3}}\right)$ & Density $\left(\mathbf{k g} / \mathbf{m}^{\mathbf{3}}\right)$ \\
\hline $1: 1: 0.5$ & 7.2 & 0.0093 & 774.193 \\
$1: 1: 1$ & 6.6 & 0.0093 & 709.677 \\
$1: 1: 1.5$ & 6.1 & 0.0093 & 655.9139 \\
\hline
\end{tabular}

\subsection{Fire Resistance Test}

According to the Indian standard (IS: 1077-1992) a block which is used for construction should not be flammable in open flame, so this test was carried out for the hollow blocks. The following are the steps involved in this test.

- First, the brick was wiped with cloths and all the foreign matters were removed.

- Then the flammable sticks were fired. After that, the blocks were held on the flame for five minutes.

- After five minutes fixing was stopped and the blocks were observed.

From the above test, it was observed that the hollow blocks did not burn with an open flame. They smoldered like charcoal. But these blocks would be reduced to ashes after burning several hours. If the interior plaster and exterior stucco is provided on the blocks, the blocks won't burn. The only weak point is inside the block, near electrical outlets, switches and other places where wires gives through walls, into boxes etc. Properly wired places never cause fire.
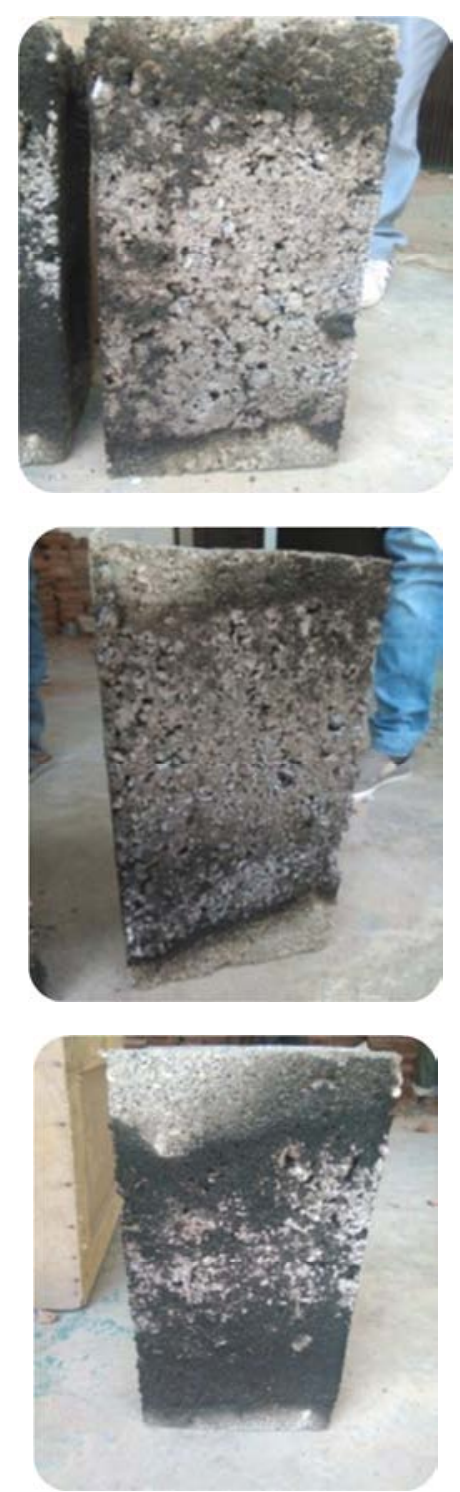

Figure 12. Papercrete hollow blocks after fire resistance test. 


\subsection{Results for the Cost Comparison}

For the production of ordinary $\mathrm{HCB}$ the price goes to 11.67 birr per unit block but for the production of the Papercrete the unit price is 7.57 birr. The price of the paper is considered to be zero because it is a material that is no longer required and ready to be dumped or burned but if peoples want to sell the paper by being aware of its benefit for business they can sell it but in way that the produced Papercrete hollow block is competitive by price with that of ordinary HCB. They only have to follow simple marketing idea "if you want affordable market you need to have a demand that can afford".

\section{Conclusion}

Finally we can conclude that Papercrete can be applicable for non-load bearing wall, if some amount of paper is reduced and it requires plastering. If we see it in economic view Papercrete block consists of recycled material so that cost is very low compared to conventional blocks. Additionally Papercrete can easily be molded into any shape, blocks are much easier for someone to lift to any desired height and very good surface finish can be achieved and it also has good fire resistance. The weight of this block is $50 \%$ lesser than conventional HCB, Due to less weight of these blocks, the total dead load of the building will be reduced. Since, the waste papers are used; it will reduce the landfills from being damp site and pollution caused due to the burning of paper. But these blocks are not suitable for water logging and external walls. It can be used in inner partition walls and They are termite proof; hence the paper was mixed with cement in Papercrete blocks. Generally the more the paper optimum the better the strength, but for higher strength the more the cement.

\section{References}

[1] K. Anandaraju, B. JoseRavindra Raj, R. VijayaSarathy (Jun 2015), "Experimental Investigation of Papercrete Brick", International Journal of Machine and Construction Engineering, Vol. 2, pp1-8.

[2] T. Subramani, V. Angappan, (May 2015), “Experimental Investigation Of Papercrete Concrete", International Journal of Application or Innovation in Engineering \& Management (IJAIEM), Volume 4, Issue 5, pp1-10

[3] http://the contructor.org/concrete/...light-weight concrete.[last accessed 8 June 2016]

[4] Joo-Hong Chung, Byoung-Hoon Kim, Hyun-ki Choi and Chang-Sik Choi (2015), "Development of Papercrete due to Paper mixing ratio", Hanyang University, Seoul, Korea, pp133-791
[5] http://www.greenhomebuilding.com/papercrete.[last accessed 16 may 2016]

[6] Kokkinos M.(2011), "Papercrete; another façade cladding material", (MSc thesis) Delft: Technical University of Delft, pp. 2-48

[7] Lyons A., (2008), "Materials for architects and builders", (4th edition). China: Elsevier, pp. 401-402

[8] Peters S. (2011) "Materials Revolution; Sustainable multipurpose materials for design and architecture". Germany: Birkhäuser, p. 38-101

[9] Ali A., Hashmi, H. N. \& Baig, N. (2013), "Treatment of the paper mill effluent - A review", Annals of Faculty Engineering Hunedoara - International Journal of Engineering 11 (3), 337-340.

[10] https://en.m.wikipedia.org/wiki/paper.

[11] http://en.m.wikipedia.org/wiki/water.

[12] Akinwumi, olasunkanmi (2014), "Structural Evaluation of Lightweight Concrete Produced Using Waste Newspaper and Office Paper "ISSN- 2224-5790 (PAPER), ISSN 225-0514 (ONLINE), Civil and environmental Research Volume No 6, No 7-2014.

[13] Akinwumi (2014), "Earth building construction processes in Benin City, Nigeria and engineering classification of materials used", Indian Journal of Traditional Knowledge 13 (4).

[14] Wallbaum, H. \& Buerkin, C. (2003), "Concepts and instruments for a sustainable construction sector", Industry and Environment, 26, pp53-57.

[15] Seyfang, G. (2010), "Community action for sustainable housing: Building a low-carbon future", Energy Policy 38, 7624-7633.

[16] M. S SUGANYA (April 2012), "Lightweight bricks-made up of waste papers" International Journal of Computer \& Organization Trends-Volume 2, Special Issue 2, ISSN-22492593, Number-2

[17] M.ramegowda, k.prasanna (October 2014), "Development and Study of Some Properties of Papercrete Concrete "Indian Congress Journal (ICJ), Special Issue on "Sustainability Development"-volume 88,

[18] B. J. Fuller, A. Fafitis and J. L. Santamaria. (May 2006), "The Paper Alternative”, ASCE Civil Engineering Vol. 75 No. 5 pp. 72-77.

[19] G.v.s. Siva, p.p.admanabha, m.swathi, p.d.v.kirankumar, t.praveenraja, m.naveen (2015), "study and behavior of some properties of Papercrete brick with modular brick", International Journal of Engineering Research-Online, Vol. 3, Issue. 3 .

[20] Eleni Ganotopoulou (2014), "BIODEGRADABLE MATERIALS", A research and design handbook; enhancing the use of biodegradable materials on building's envelopes in the Netherlands, MSc. Thesis, Technical University of Delft, Netherlands. 